\title{
Climate Change Adaptation, Urban Flooding and Water: Old Problems, New Challenges for Planners and Architects
}

\author{
João Pedro T. A. Costa \\ Architect; PhD. Professor, School of Architecture and CIAUD - Research \\ Centre of Architecture, Urbanism and Design, University of Lisbon.
}

The effects of global warming on sea level rise is one of the most challenging immediate futures faced by planning and the design disciplines. These effects can lead to grave consequences in coastal cities and is a growing field for policy and plan making in the United States and across the globe. Joao Pedro Costa brings us this debate from an European perspective, discussing the challenges and new creative solutions.

\begin{abstract}
T he occurrence of flooding in cities has been a part of the urban design and architecture agendas for a long period of time. In the 20th century, defensive approaches to such phenomenon increased alongside society's growing confidence with infrastructural capacities. More specifically, urban flooding was mainly an infrastructural issue, and hence had the responsibility to deal with such respective hazards. Cities, buildings, and public spaces were, moreover, directed at addressing a major concern: the control of water and circumventing its dynamic threats within the city.
\end{abstract}

Amongst other typologies of water defensive infrastructures, dikes, pumping stations, flexible water barriers, and underground deposits were revered as inevitable, and thus given priority over urban design and architectural agendas. Indomitably, the priority was to save lives and protect economic assets and design disciplines were thus obliged to accept this established precedence.

Nevertheless, a change in this paradigm has been witnessed in recent years. In conjunction with the emergence of the climate change adaptation agenda, the customary use and dependence on heavy infrastructure started to be substituted by the increasing convergence between urban development and encircling natural systems. Although the sustainability agenda has arguably reinforced humankind's role within cities, the reason for this substitution was not the result of his "romantic" reinvention. Instead, it is the result of the recognition and ongoing verification that: (1) natural systems frequently reveal themselves as more resilient to hazards, hence presenting a more robust progression through time; and (2) the more dependent a city and society is upon its engrained infrastructure, the worse the disaster shall become in the case of the infrastructure's failure.

\section{Climate Change Adaptation as a Contemporary Agenda}

Climate change made its first appearance in international debate during the last quarter of the 20th century. This was the result of an emerging new international agenda that was formed as a result of the following key moments: (i) Wally Broecker's pioneer paper in 1975; (ii) establishment of the International Panel on Climate Change (IPCC) in 1988; (iii) followed by the IPCC's First Assessment Report in 1990; and, (iv) the Framework Convention on Climate Change held in Rio de Janeiro in 1992 (United Nations, 1992). Delineated through a top-down approach, climate change was dominated by mitigation policies whereby the United Nations emanated protocols that were then downscaled in the different countries, regions, cities, and economic activities. Furthermore, the signing of the Kyoto Protocol in 1997 most likely also served as a crucial moment for this mitigation policy, one which committed its signing countries to internationally binding reductions in greenhouse gas emission targets for the period between 2005 and 2012 (United Nations, 1998).

During such period, the climate change adaptation policy was not a priority. Instead, the focus was on reducing emissions and increasing carbon sinks, with the hope that mitigation attitudes would be able to stop the expected effects. Additionally, it was hoped that there would be an established convergence between economic activities and the planet's long-term sustainability. However, this focus has shifted in recent years and the second half of the 2000s decade witnessed the emergence of the adaptation agenda. As the scientific community disseminated more confident climate change scenarios for the medium to long-term and observed the continuous growth of global greenhouse gas emissions, spatial planning began to consider the consequences of these changes and how they could be incorporated into planning processes (Blunden \& Arndt, 2014). ${ }^{1}$ Followed by several

\footnotetext{
${ }^{1}$ According to the 2013 State of the Climate report by the American Meteorological Society, global greenhouse gas concentrations continued to rise in 2013, once again reaching historic high values, with atmospheric CO2 concentrations reaching a global average of 395ppm and, for the first time since measurements began in 1958, daily concentrations exceeded 400ppm (Blunden \& Arndt, 2014).
} 
national and regional studies, and annual climate reports, the IPCC's Fourth Assessment Report in 2007 had a significant impact upon academia, local administration, and media. The message was guileless, yet ardent: The climate is already changing.

Nonetheless, the key factor for this new conscience was the occurrence of various extreme climatological events. Focusing on waterfronts, the impacts of Hurricane Katrina in August 2005 upon New Orleans, leading to more than 1,800 deaths and 250,000 evacuees, was the ultimate eye-sawing and irrefutable evidence that:

"If Hurricane Katrina taught us anything, it is that the worst-case can happen. For the first time in human history, science has given us the ability to peer into a crystal ball of numbers and models and see what kind of a climate we'll be living in by mid-century if we continue to emit carbon at our current levels." (Cullen, 2010, p. xvii)

This again enforced the idea that the climate was in fact changing and, moreover, that extreme scenarios were in fact possible.

As a result of Hurricane Katrina and the Dutch-American collaboration, the Second Dutch Delta Commission was appointed to develop a new integrated vision for the territorial development of the Netherlands. The 2008 report "Working together with water. A living land builds for its future," marked a profound change in national policy that had been established for 200 years (Deltacommissie, 2008). More specifically, the new paradigm "working with nature" replaced the previous "fighting against the water," with a medium and long-term vision which would include adaption orientations for climate change scenarios. In the years 2008, 2009, and 2010, several other countries, regions, and cities developed their climate change adaptation agendas. Some national agendas inaugurated new policies, while others made use of previous documents and combined them under a coherent umbrella, such as in the United Kingdom (Department for Environment, Food and Rural Affairs, 2008). ${ }^{2}$

Based on projected climate change scenarios, various cities were particularly orienting their strategies to the most relevant problems and existing local planning approaches. This approach is exemplified by: (1) New York City, which is mainly concerned with the change of patterns and impacts of extreme phenomena (New York City Panel on Climate Change, 2010); (2) San Francisco, which is confronting projected impacts in its Bay and encircling key occupations, such as principal infrastructures, networks, and priority development zones (San

\footnotetext{
${ }^{2}$ United Kingdom was one of the pioneer countries on climate change adaptation. The report Adapting to Climate Change in England: A Framework for Action was more than a new policy, it was a policy document oriented to join several initiatives of the last decade and coordinate them under a common approach (Department for Environment, Food and Rural Affairs, 2008).
}

Francisco Bay Conservation and Development Commission, 2009); (3) Rotterdam, which is developing new orientations for flood management, retaining the water inside consolidated urban areas, and recovering new space for the river (Rotterdam Climate Initiative, 2010); and lastly, (4) London, which is preparing the future adaptation of its existing infrastructures, such as the Thames Barrier, and also developing territorial units with orientations for flood risk management (Environment Agency, 2009; Mayor of London, 2010).

Although each city develops its own climate change adaptation policy with a specific methodology, some common orientations can be observed (Costa, 2013). The first consists of the definition of climate change models for the specific territory and downsizing global, national, and sometimes regional studies. This delineation's objective is to establish medium and longterm scenarios to work with that further consider the inferred uncertainty regarding future projections and definition of tasks. The second focus tackles the application of these very scenarios to local territories, where attempts are made to assess the impacts of climate change upon a specific site. This inquisitive exploration is the analytical pillar of the "what if" agenda. The third focus consists of the adaptation strategy itself, which launches the exploration into other existing adaptation strategies or into past solutions that dealt with similar impacts. This approach is described by the World Bank as defining a longterm plan "your own way" (Prasad et al., 2009).

\section{Urban Flooding: The Role of Infrastructure, Urban Design, and Architecture in Facing New Challenges}

It is in this recent context that new approaches are emerging to address the phenomenon of urban flooding. The new challenges can be synthesized into six main topics:

1) Urban areas should retain as much rainwater as possible, including in flash flood situations. This would approach a "selfsufficient" balance. Moreover, it is essential to address such stresses in downstream urban areas, particularly in the city's waterfront. Not only do they suffer from issues of flash flooding, they also might fall victim to the decreased capacity to discharge rainwater into the river given future climate change scenarios. This is particularly tangible given the estimations of sea level rise, or due to the steep increase of such phenomena. Hence, this objective prompts new challenges both to urban design and architecture. Nevertheless, this presents a new realm of opportunity whereby creativity can be developed in conjunction with recovering former practices, including those that were frequently abandoned due to an "extreme faith" in infrastructure.

2) Public spaces can become particularly key elements in retaining rainwater without the need for heavy infrastructure. This propagates the creation of multifunctional spaces not only prepared for everyday leisure or other exterior activities, but to also handle retention roles while simultaneously enforcing safety within the public realm. 
3) The multifunctional use of valley streets should be part of urban design approaches. Particularly in cities with strong topographies, the streets along the valley lines in consolidated urban fabric, corresponding to former water lines, tend to be corridors of considerable strain in events of flooding. In extreme cases, the pluvial drainage system might exceed its capacity and cause street flooding. Given these circumstances, this may lead to the formation of a fleeting artificial, yet destructive river. Both in existing and future cases, as projected by future climate change scenarios, urban design must acknowledge this unwavering reality and formulate controlled flood situations.

4) Cities should no longer grow by reducing the river's flooding basins. For example, dikes should no longer advance on rivers in order to protect new or renewed urban areas. Consequently, and particularly in urban waterfront renewal operations, new urban design solutions are required to assure safe new urban areas located outside the respective dikes or protected areas.

5) Existing "protected" waterfront areas should incorporate new resilient design solutions, thus increasing adaptability and reducing risk. This is relevant both for the future scenarios of climate change and for future extreme situations if defensive, pluvial drainage or other types of infrastructure are to fail. As a result, the exploratory and analytical "what if" agenda must gain increased importance in urban planning.

6) Buildings are also imperative when addressing urban flooding. An architectural project cannot take place without context and several architectural responses can be found at the building scale, namely: (i) creating flood resilient buildings; (ii) retaining rainwater in tanks given an extreme phenomenon; (iii) preparing the building to deal with possible flood situations; and lastly, (iv) offering shelter and safe urban connections in specific cases of flooding.

It is worth noting that the "working with nature" approach does not imply that infrastructure is not needed, but that it should be used with moderation and in conjunction with "natural" design solutions. Additionally, it is also inferred that the elevated dependence on infrastructure should be avoided as much as possible, as its potential failure could imply the invigoration of the very threat it was created to neutralize.

It can be argued that this ultimately translates into a maturing relationship between society and infrastructure. In other words, if the 20th century was marked by the incredible increase of society's technological capacities and by his intentions to control every urban problem with regards to infrastructure; then, the 21 st century would be marked by the recovery of light design solutions to deal with the same issues. In other words, the relationship after the turn of the century is one that induced a more moderate approach towards heavy infrastructure, one which also called upon the cooperative relationship with the continuous growth of technological capacity. As a result, the confidence in heavy infrastructure of the "young technological human" could arguably now give way to a more matured practice, one that also calls upon the use of natural system solutions when respectively applicable.

\section{Water and Environment, an Increasingly Important Agenda for Urban Design and Architecture}

Together with the emergence of natural system design solutions regarding urban flooding, the development of the sustainability agenda during the last decade allowed for the establishment of new relations between the environment, water, and the city. Water is part of the city today, firstly through the recovery of waterfront areas during the last quarter of the 20th century (associated with large urban regeneration interventions) (Meyer, 1999). Secondly, by the importance that these elements assumed in planning and at the proximity scales, which resulted in an improved local environment; where its use represents quality of life, and competitiveness in areas such as the economic, leisure, and tourism markets.

For urban design, public space design, and architecture, natural systems become a central agenda as they can often integrate water and green areas. Nevertheless, this does not imply that the agenda is artificial. On the contrary, values such as the promotion of local landscapes, the use of autochthonous vegetation, the reinforcement of heritage approaches (resulting in the reuse of former buildings and infrastructures as an alternative to urban renewal), and the reduction in space maintenance requirements, are all evidence of the "working with nature" principles. Furthermore, this evidence enforces the augmented maturity of humankind in relation to our surrounding environment, one which is not fixated on its control, but instead living in harmony with it.

Urban design and architecture have been naturally incorporating these new values. "Living with nature" has become a societal requisite in developed countries, which has been a demonstration of the dynamic relational transformation of humanity, one that has already been expressed in some institutional documents in the last decade. ${ }^{3}$ "Working with nature" approaches have found, therefore, an existing practice with convergent objectives, one which ultimately has opened new perspectives for architecture and urban design.

\section{Designing a New Relationship with Water?}

It is in this context that contemporary urban design has found new horizons of creativity in its relationship with water. This relationship is one that has resulted from the fertile combination of three approaches: (1) recovery of former knowledge in the very site itself, or from cases of other geographical locations that witnessed similar obstacles; (2) development of technological innovations to answer construction problems, which have enabled the possibility to implement new ideas; and lastly,

\footnotetext{
${ }^{3}$ For example, the European Landscape Convention (also known as the Florence Convention, the city where it was adopted in 2000).
} 

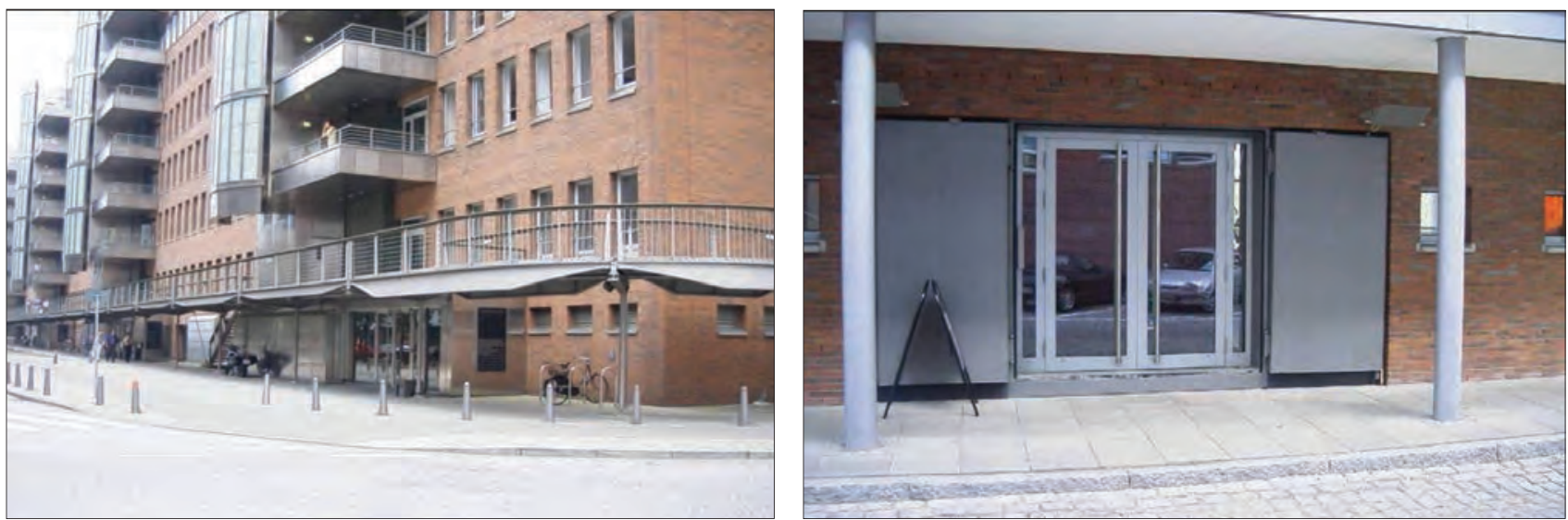

Figures 1a \& b: Flood resilient urban design at Hamburg's HaffenCity a solution for flood resilient urban design area: the upper level circulation network and the protection systems at ground level. (photos by the author and by Jan-Moritz Müller)

(3) unmistakable basic conditions to explore creativity, which enables broader and "out of the box" thinking.

The combination of these three approaches has led to several relevant examples, those that simultaneously answer to urban flooding, sustainability, and the improvement of local environments. Varying between different scales and typologies, various exemplars shall be here discussed.

Starting with an example of urban design, the HaffenCity's 255 hectares regeneration of former port and industry areas in Hamburg (Figure 1), decided to maintain its position outside the dikes. The implementation of resilience through what was called the "B plan of the city" (Costa, 2013) combines the everyday interactive use of the proximity to the water on the Elbe River, increasing the site's environmental quality with controlled answers to local flooding through urban design. The entire urban area is prepared to accommodate urban flooding due to its design solutions both at the urban and architectural scales, hence avoiding damage and certifying the continuity of normal urban activities. Anticipating flooding situations and their influence upon accessibility, infrastructure, buildings, public spaces, and all other functions is part of an integrated approach, which accepts regular flooding. Moreover, it refuses the construction of dikes, and therefore does not lead to the reduction of the Elba's flood basin.

Downscaling now to public space design, Rotterdam is a living example of innovation. Both Wetersingel, exemplifying an urban corridor (a street), or the Water Square that exemplifies a centrality (a square) are conceived as multifunctional spaces. These examples demonstrate conjoining the design for everyday life with a functional retention basin within the consolidated and dense urban fabric.

Westersingel (Figure 2), was not only a renaturalization of a former channel that was piped during the 20th century in order to permit car circulation, it also introduced a high quality urban environment on a central axis that permitted the recovery of the channel's identity within the city. Furthermore, it also allowed the construction of a flood retention bay through the creation of a down-level platform of public space closer to the water plan. Consequently, this exploited the relationship with surrounding environmental qualities and safely supports flooding without any damage to the urban fabric at ground level.

The Water Square is both a creative and innovative project (Boer, Jorritsma, \& van Peijpe, 2013) (Figures 3a \& b). It answers to the previously mentioned need for a consolidated urban area to have a "self-sufficient" balance, being able to both retain water in extreme events and also neutralize the stress on downstream areas. Its design encompasses a neighborhood approach, through the creation of channel networks, and a site approach, through the development of a multifunctional public square. The result is the amalgamation of a down-level platform for sport and leisure uses that can support everyday life, whilst simultaneously, safely handling flooding events.

A similar logic can be seen in some of Barcelona's examples, both in street corridors and square centralities. In this case, rainwater retention respects not only the local neighborhood,

Figure 2: Rotterdam's Westersingel: a renaturalized channel with its flood retention bay. (photo by Maria Matos Silva)

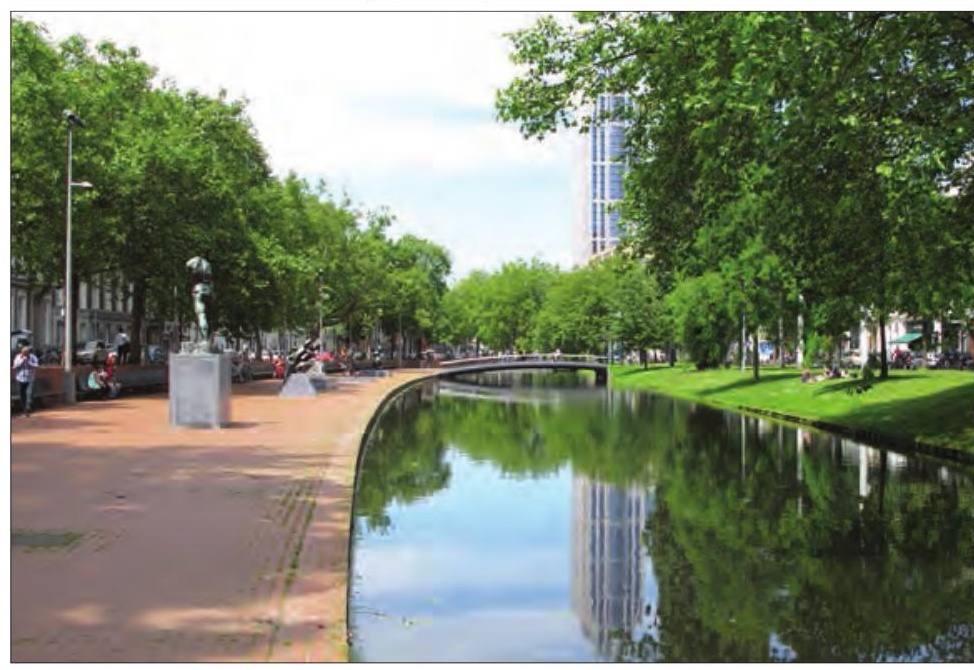




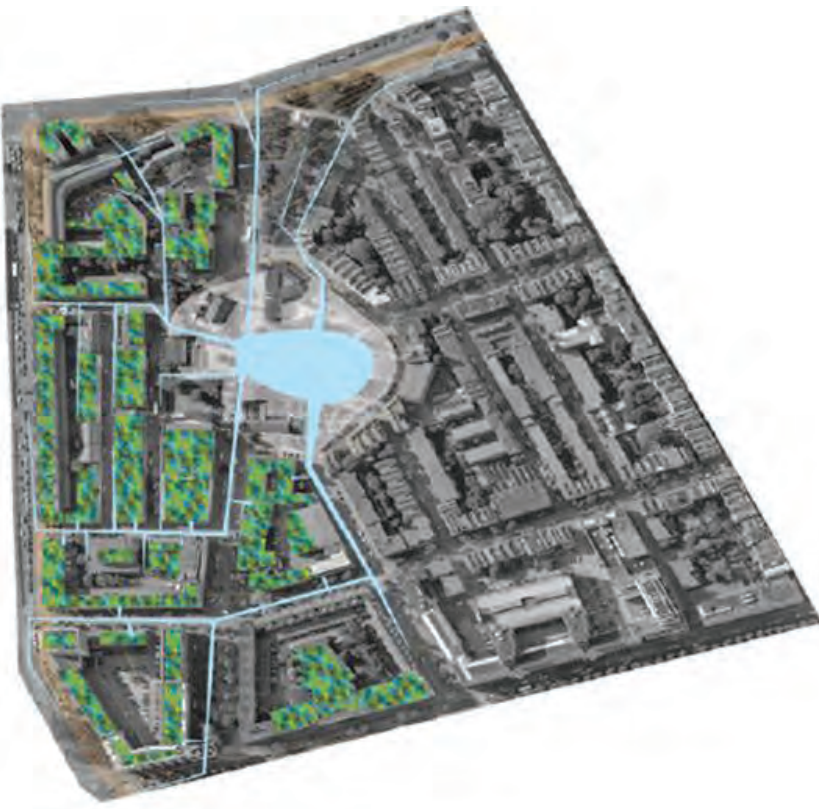

but also the large upstream urban fabric. As a result, heavy infrastructure is needed to accommodate large quantities of water in short periods of time, which, in turn, avoid problems downstream. The multifunctional solution consists of the construction of large water deposits underground, combined with the development of high quality public space design at city level, e.g., the Joan Miró Park (Figure 4) or the Doctors Dolsa Square (Matos Silva, 2011).

Occasionally, the design of a new relationship with water already exists in the everyday life of a city, all that is required is for it to be observed and recognized. With high topography and waterlines coming upstream in the Madeira Island, the city of Funchal regularly experiences flash flood events (Figure 5). In these cases, urban design in waterline corridors is crucial. As demonstrated by the flash flood in 2010, the common, yet considerable streambed might prove insufficient in accommodating large quantities of water. In these situations, the streets become open rivers and hence urban infrastructure,

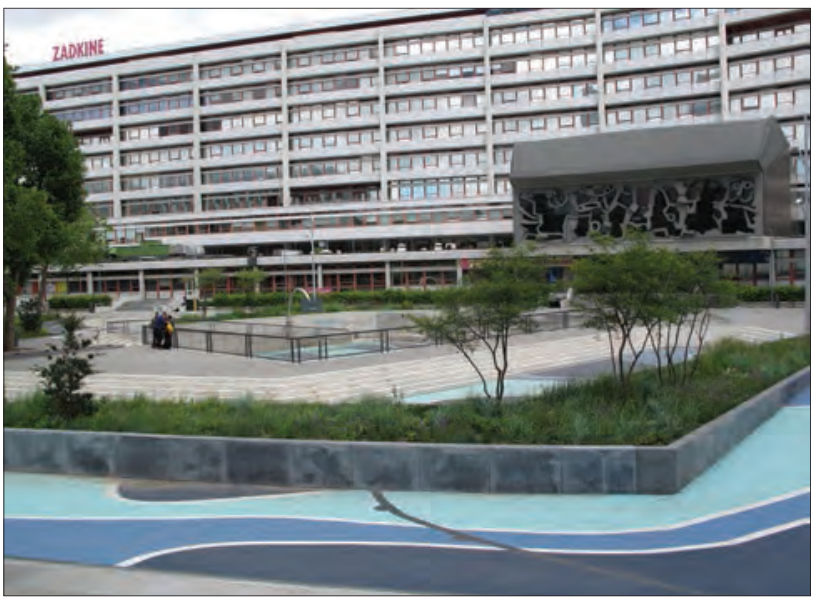

Figures $3 a$ \& b: Rotterdam's Water Square, 2010: collection of the neighborhood's storm water and retention in a multifunctional park. (courtesy: De Urbanisten, Florian Boer, Jens Jorritsma, and Dirk van Peijpe; photo by Maria Matos Silva)

planning, and public space design must take this into account. More specifically, this implies that: (1) infrastructure ensures that the waterline walls and city foundations are safe and prepared to accommodate the flooding events; (2) urban planning ensures the respective corridor is kept free, i.e. without any transversal obstacles, such as buildings or closed bridges; and lastly, (3) public space design develops multifunctional solutions which combine everyday life with the required resilience for these occasional events. It is here again that the integration of the "what if" scenarios gain their importance in urban planning. This importance is connected to the preparation of the city for future events, that, having a mid or long-term occurrence, might be very destructive if not carefully prepared for.

Focusing on innovative solutions, the contemporary design of new relationships with water includes a significant exploration and development of floating structures. Being an old concept and practice, floating structures gain a new dynamic through both their resilient capacity of floating and their high experimental potential. ${ }^{4}$ Hence, this permits a

Figure 4: Barcelona's Joan Miró Garden: a square with a high quality public space design, integrating a large pluvial water deposit underground. (photos by Maria Matos Silva and Clavegueram de Barcelona)
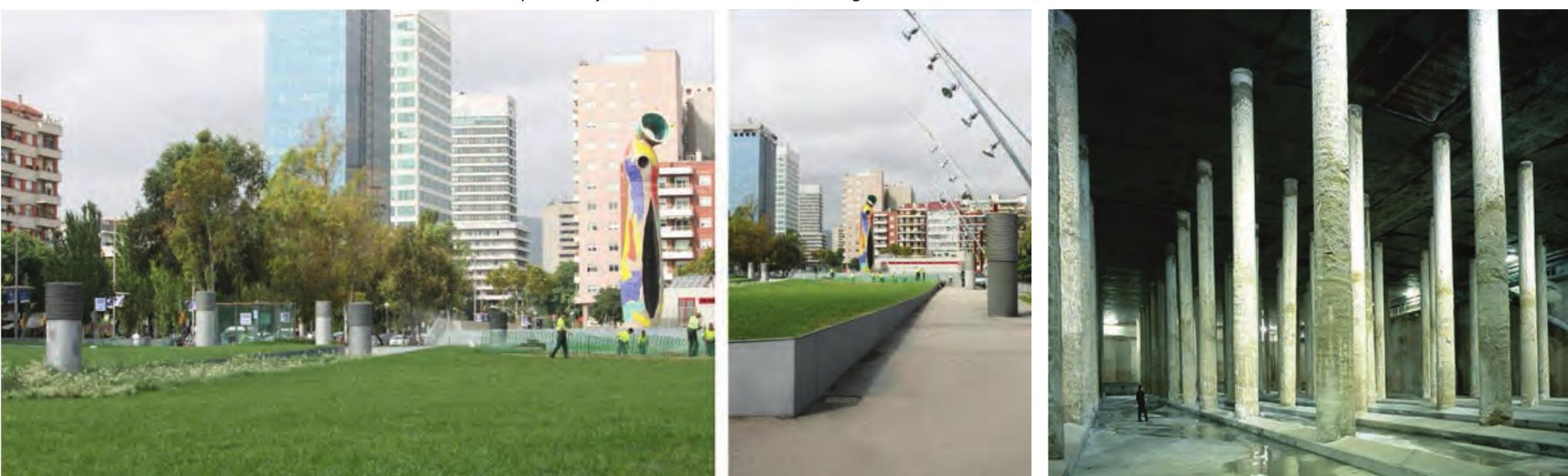


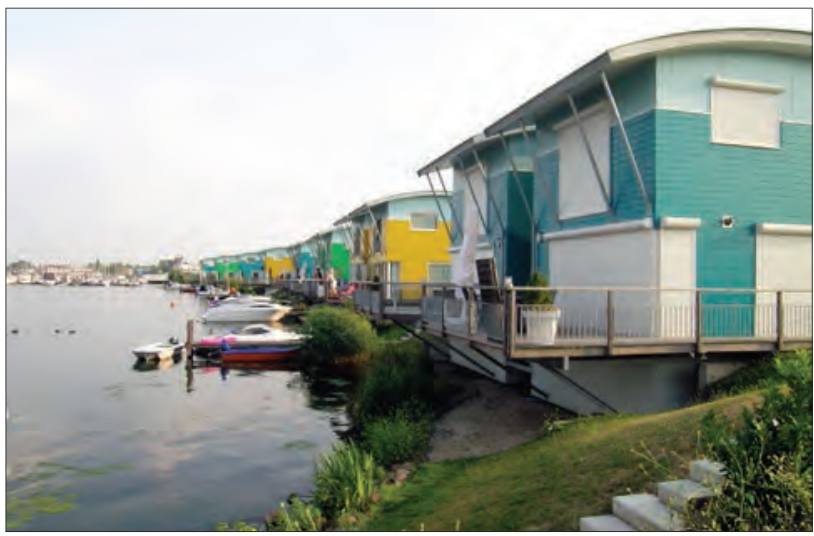

Figure 5: Netherland's Maas amphibious houses: located on firm soil, they are anchored to the site by a vertical structure and are prepared to float during a flood event. (photo: Factor Architecten and Dura Vermeer)

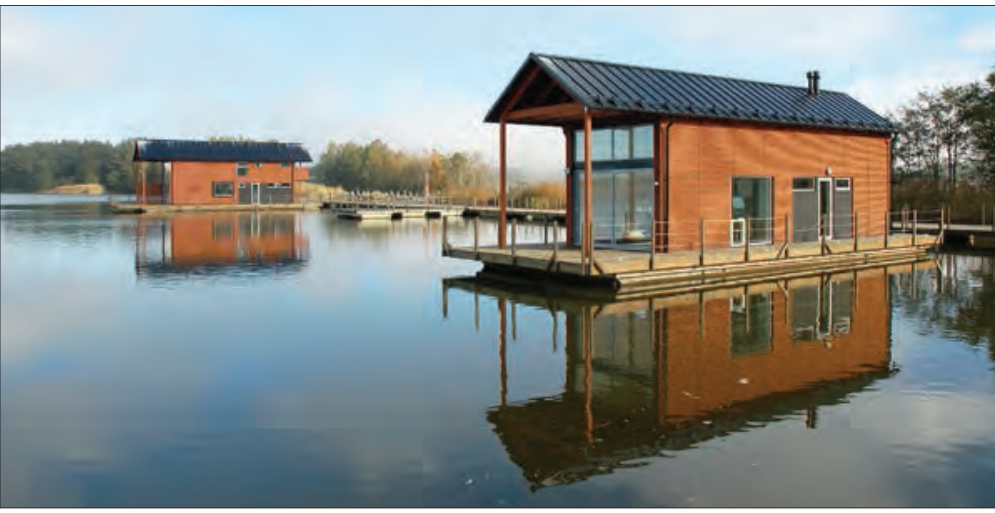

Figure 6: Finnish floating houses have an locking mechanism under their decks. (photo by Marina Housing Ltd.)

Figure 7 a \& b: Rexwal's floating SPA, Germany. (photo by Deutshe Composite GmbH)
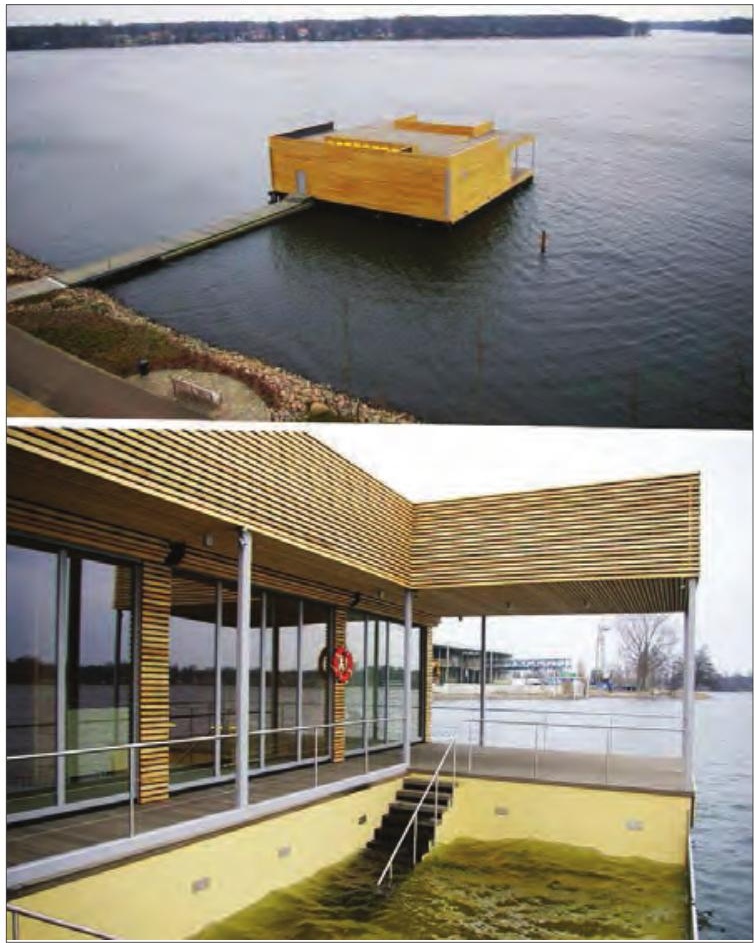

greater and more efficient proximity to water that otherwise would not be viable for traditional constructions. The advance of technology has mainly contributed to determining the type of floating structure (both in concept and material), structural configuration, and light construction methods. The last decade witnessed a large expansion of these type of constructions, mainly through: (i) construction of small buildings with small scale floating structures; and (ii) exploration of floating mega structures through learning lessons from existing constructions such as sea oil platforms, with the purpose of exploring the design of futuristic utopias.

The creation of floating buildings has undergone an important development in recent years, and in numerous geographical locations. As expected, the Netherlands is one of the leading countries in this subject, although it is also worth acknowledging other very interesting cases in countries such as Germany, Finland, France, United States, and although with a different scope, projects in Vietnam and Bangladesh. It should also be recognized that the development of these concepts is also supported by international aid. Although others exist, two main concepts shall be here discussed. The first consists of permanently floating constructions that are fixed to the land through a specific technology. The second focuses on amphibious constructions that are prepared to float in high waters in light of flooding events. Under normal circumstances, the amphibious constructions are located on the ground, but they also have technology for the guides to maintain a fixed structure when it changes level. Both the 2004 Dutch Maas amphibious and floating houses, by Factor Architecten and Dura Vermeer, with a vertical guide lock mechanism (Figure 5), and the 2010 Finish Floating Villas by Marina Housing Ltc., with an inferior lock mechanism (Figure 6), illustrate such techniques.

Revealing extreme creativity and oriented more towards exploring the versatile qualities of the proximity to water, the 2010 German Floating SPA in Rexwal by Deutshe Composite $\mathrm{GmbH}$ designed a cold bath directly upon the lake (Figure 6). With a similar creative flair, the 2004 Badeschiff floating pool in Berlin by Spanish AMP Architects installed a comfortable swimming facility all year round at river level, giving the illusion that one was in fact swimming in the Spree (Figure 7). Both of these examples show the almost unlimited potential of design innovation in exploiting this novel relationship with water.

Finally, we can conclude that a new relationship between society and water is emerging, namely with urban infrastructure, planning, public space design, and architecture.

\footnotetext{
${ }^{4}$ One can mention, among several other examples: (1) the biblical example of the Noah's Arch; (2) the local tribe floating islands by the Uros in Peru and Bolivia, built with local vegetation; (3) The Teatro del Mondo architectonic gesture, by Aldo Rossi, a floating building designed for the 1979 Venice Biennale which recovered a former venetian practice of the 18th century; or, (4) some floating structures developed in the United States during the 19th century, such as Philadelphia's floating church.
} 


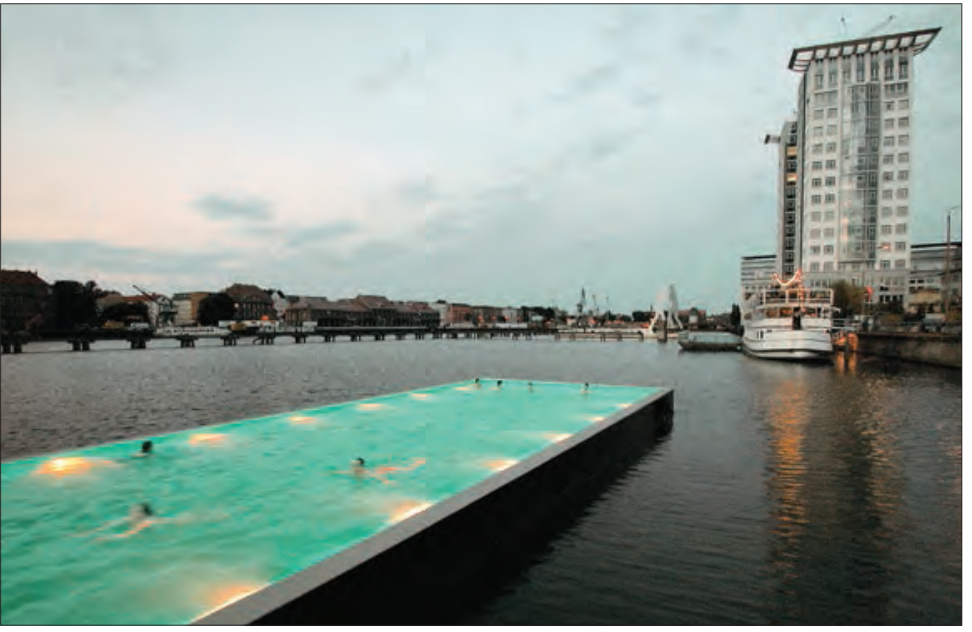

Figure 7: Berlin's floating pool: comfortable swimming is offered the entire year at the river level; roofless in the summer and covered during winter. (photo by AMP Architects, S. Lorenz and G. Wilk)

Innovation and the recovery of former knowledge are hence combined into a new agenda of multidisciplinary articulation and creativity. This multifaceted and ever-maturing agenda is one that has directly originated from the exploration of: (i) water's diverse and bountiful capacities in today's contemporary society; (ii) the increase of resilient approaches to urban flooding; and (iii) the new dimension acquired by flooding under the emerging climate change adaptation agenda. Furthermore, the role of heavy infrastructure is also itself under reevaluation. Although it is still recognized as necessary, it is correspondingly acknowledged that high dependence on it is acrimonious with the resilient city. As an alternative, the development of a "living with nature" approach and the use of natural systems is thus unequivocally gaining substantial weight in contemporary design.

Accordingly, if the sustainability agenda was to open such horizons, the concomitant resilience and climate change agendas would indubitably reinforce their own adaptability capacities-hence strengthening the potential to combine environmental quality and everyday life with risk reduction.

\section{References}

Blunden, J., \& Arndt, D. S. (Eds.). (2014). The state of the climate in 2013. Bulletin of the American Meteorological Society, 95(7), S1-S238; Retrieved from http://www.ncdc.noaa.gov/ bams-state-of-the-climate/2013.php

Boer, F., Jorritsma, J., \& van Peijpe, D. (2013). De urbanisten and the wondrous water square. Rotterdam, Netherlands: 010 Publishers.

Broecker, W. S. (1975). Climatic change: Are we on the brink of a pronounced global warming?. Science, 189(4201), 460-463. doi:10.2307/1740491
Costa, J. P. (2013). Urbanismo e adaptação às alterações climáticas, as frentes de água. Lisbon: Livros Horizonte.

Cullen, H. (2010). The weather of the future: Heat waves, extreme storms, and other scenes from a climate-changed planet. New York, NY: Harper Collins..

Department for Environment, Food and Rural Affairs. (2008). Adapting to climate change in England: A framework for action. London, England.

Deltacommissie. (2008). Working together with water. A living land builds for its future. Findings of the Deltacommissie. Retrieved from http://www.deltacommissie.com/doc/deltareport_full.pdf

Environment Agency for the Thames Region. (2009). Thames Estuary 2100: Managing flood risk through London and the Thames Estuary - Consultation document. London, England.

Intergovernmental Panel on Climate Change. (1990). IPCC First Assessment Report. Retrieved from http://www.ipcc.ch/ publications_and_data/publications_and_data_reports. shtml

Matos Silva, M. (2011). El modelo Barcelona de espacio público y diseño urbano: Public space and flood management, dipòsits d'aigües pluvials (Master's thesis). Barcelona: University of Barcelona. Retrieved from http://hdl.handle. net/2445/17762

Mayor of London. (2010). The draft climate change adaptation strategy for London. London: Greater London Authority.

Meyer, H. (1999). City and port: Urban planning as a cultural venture in London, Barcelona, New York and Rotterdam. Rotterdam, Netherlands: International Books.

New York City Panel on Climate Change. (2010). Climate change adaptation in New York City: Building a risk management response. Annals of the New York Academy of Sciences, 1196.

Prasad, N., Ranghiei, F., Shah, F., Trohanis, Z., Kessler, E., \& Sinha, R. (2009). Climate resilient cities: A primer on reducing vulnerabilities to disasters. Washington, D.C.: The World Bank.

Rotterdam Climate Initiative. (2010). Rotterdam Climate Proof Adaptation Programme 2010. Retrieved from http://www. rotterdamclimateinitiative.nl/documents/RCP/English/ RCP_ENG_def.pdf

San Francisco Bay Conservation and Development Commission. (2009). Living with a rising bay: Vulnerability and adaptation in San Francisco Bay and on its shoreline. Draft report. San Francisco, CA. Retrieved from http://bairwmp.org

United Nations. (1992). United Nations framework convention on climate change. Retrieved from http://unfccc.int/ key_documents/the_convention/items/2853.php

United Nations. (1998). Kyoto protocol to the United Nations framework convention on climate change. Retrieved from http://unfccc.int/kyoto_protocol/items/2830.php 